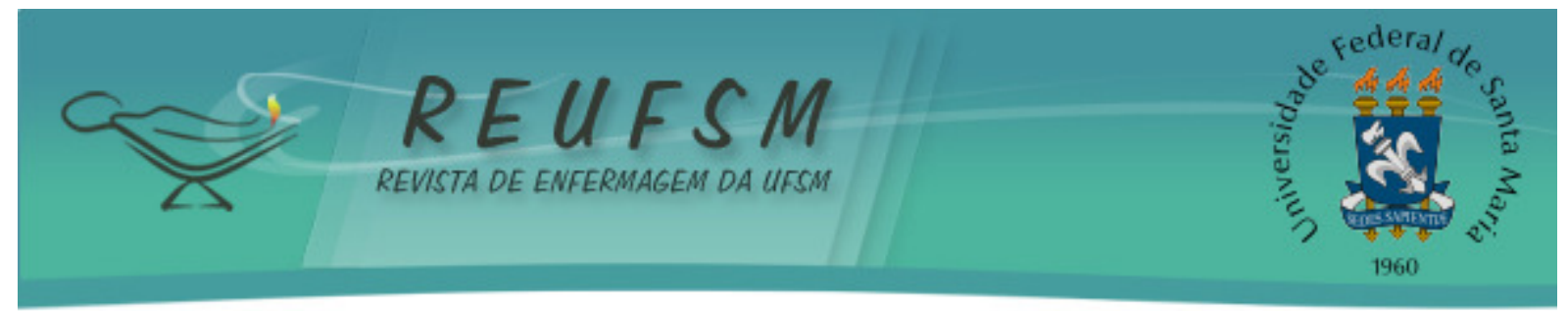

ARTIGO ORIGINAL

\title{
MEU FILHO ESTÁ COM CÂNCER: MUDANÇAS VIVENCIADAS PELAS CRIANÇAS SEGUNDO AS MÃES
}

MY SON HAS CANCER: CHANGES EXPERIENCED BY CHILDREN ACCORDING TO THEIR MOTHERS

MI HIJO TIENE CÁNCER: CAMBIOS EXPERIMENTADOS POR LOS NIÑOS SEGÚN LAS MADRES

Denise Alves Moreira ${ }^{1}$

Eva Flávia Mendes Freire ${ }^{2}$ Valessa Gizele Ramos de Oliveira ${ }^{3}$ Patrick Leonardo Nogueira da Silva ${ }^{4}$ José Ronivon Fonseca

Doi: $10.5902 / 2179769210435$

RESUMO: Objetivo: identificar as mudanças vivenciadas por crianças com câncer, segundo a percepção de suas mães. Método: trata-se de um estudo descritivo-exploratório. Utilizou-se uma entrevista semiestruturada às mães das crianças com câncer e atendidas por uma Fundação Norte Mineira. Resultados: as mães relatam que as crianças com câncer passam por muitas mudanças emocionais. 0 câncer ainda afeta a vida social e escolar. Alterações fisiológicas foram relatadas pelas mães. Considerações finais: conhecer a criança com câncer e intervir nas mudanças dos vários campos da vida destes pacientes e de seus familiares pode contribuir na eficácia do tratamento.

Descritores: Neoplasias; Criança; Enfermagem oncológica; Relações mãe-filho.

ABSTRACT: Aim: to identify the changes experienced by children with cancer, according to their mothers' perceptions. Method: it is a descriptive, exploratory study. A semistructured interview was used with mothers of children with cancer who are assisted by a Fundação Norte Mineira. Results: the mothers reported that the children with cancer undergo many emotional changes. Cancer still affects social and school life. Physiological changes were reported by these mothers. Final Considerations: knowing the child with cancer and intervening in the changes of the various fields of the lives of these patients and their families can contribute to the effectiveness of the treatment.

Descriptors: Neoplasms; Child; Oncology nursing; Mother-child relations.

RESUMEN: Objetivo: identificar los cambios experimentados por los niños con cáncer, según las percepciones de sus madres. Método: se realizó un estudio descriptivo y exploratorio. Se utilizó una entrevista semiestructurada a las madres de los niños con cáncer y atendidas por una Fundación del Norte de Minas. Resultados: las madres relataron que los niños con cáncer experimentan muchos cambios emocionales. El cáncer sigue afectando la vida social y escolar. Cambios fisiológicos fueron relatados por las

\footnotetext{
${ }^{1}$ Enfermeira. Faculdades Unidas do Norte de Minas/FUNORTE. Montes Claros, Minas Gerais, Brasil. E-mail: denise_alves7@hotmail.com

${ }^{2}$ Enfermeira. Faculdades Unidas do Norte de Minas/FUNORTE. Montes Claros, Minas Gerais, Brasil. E-mail: saude@ubai.mg.gov.br

${ }^{3}$ Enfermeira. Mestre em Ciências da Saúde. Docente das Faculdades Unidas do Norte de Minas/FUNORTE. Montes Claros, Minas Gerais, Brasil. E-mail: valessagiz@yahoo.com.br

${ }^{4}$ Enfermeiro. Especialista em Saúde da Família. Universidade Estadual de Montes Claros/UNIMONTES. Montes Claros, Minas Gerais, Brasil. E-mail: patrick_mocesp70@hotmail.com

${ }^{5}$ Enfermeiro. Mestrando em Cuidados Primários em Saúde. Docente das Faculdades Unidas do Norte de Minas/FUNORTE. Montes Claros, Minas Gerais, Brasil. E-mail: pisecfunorte@yahoo.com.br
} 


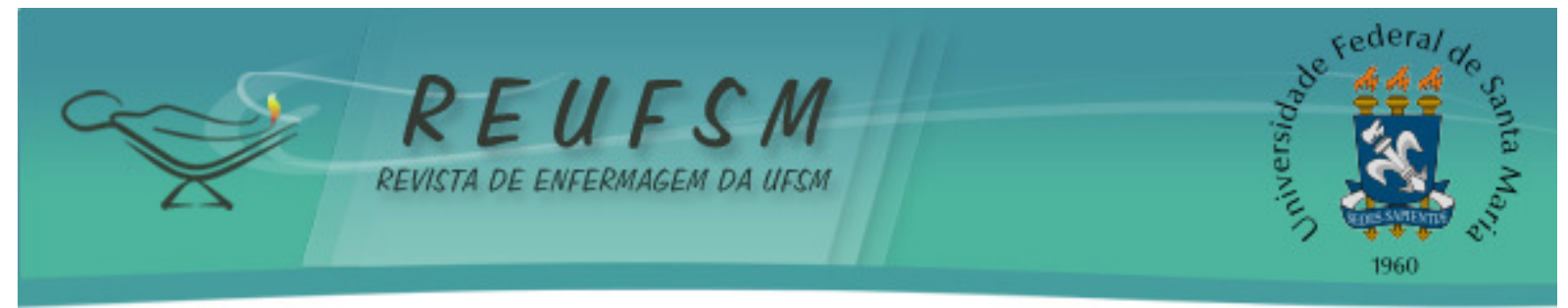

madres. Consideraciones finales: conocer al niño con cáncer e intervenir en los cambios en los diferentes ámbitos de la vida de estos pacientes y sus familiares puede contribuir a la eficacia del tratamiento.

Descriptores: Neoplasias; Niño; Enfermería oncológica; Relaciones madre-hijo.

\section{INTRODUÇÃO}

O câncer corresponde a um grupo de várias doenças que têm em comum a proliferação descontrolada de células anormais e que pode ocorrer em qualquer local do organismo. Como descrição das neoplasias mais frequentes na infância tem-se as leucemias, tumores do sistema nervoso central e linfomas. Outros tipos tumorais também acometem as crianças, sendo estes o neuroblastoma, tumor de Wilms, retinoblastoma, tumor germinativo, osteossarcoma e sarcomas. No adulto, o câncer afeta mais as células do epitélio, que recobre os diferentes órgãos, enquanto que na criança geralmente são afetadas as células do sistema sanguíneo e dos tecidos de sustentação. ${ }^{1}$

O surgimento do câncer depende da intensidade e duração da exposição das células aos agentes desencadeadores da doença. As causas de lesões genéticas e transformação neoplásica são classificadas em fatores virais, químicos, físicos e hereditários. O desenvolvimento do câncer caracteriza-se por diversas anormalidades fenotípicas, entretanto a característica de perda de regulação do ciclo celular é patognomônica a formação do tumor. ${ }^{2}$

As neoplasias são a segunda causa de mortalidade, passando nos últimos vinte e cinco anos do quinto para o segundo lugar. Projeções da Organização Mundial da Saúde estimam que em 2030, o número de mortes por câncer chegue a 23,4 milhões, contra 7,4 milhões no ano de 2004, sendo o tabagismo o grande vilão, na maioria dos casos. ${ }^{3}$

Devido ao aumento crescente na incidência dos casos de câncer, surgem novos tratamentos e mudanças no cuidado, o que gera grandes desafios. Mediante esse contexto, a enfermagem tem a responsabilidade de acompanhar o desenvolvimento do conhecimento em oncologia, principalmente através das investigações científicas, que são as peças-chave para o avanço do cuidado com o paciente oncológico. Isso contribui para que o paciente desenvolva tranquilidade, segurança, controle emocional e confiança no sucesso do tratamento. ${ }^{4}$

A comunicação pela equipe de enfermagem deve ser empregada de forma terapêutica, e o profissional deve procurar ajudar os pacientes a se adaptarem melhor às situações, identificando e atendendo suas necessidades de saúde, permitindo que eles participem do seu tratamento. Os cuidados de enfermagem ao paciente com câncer devem ser individualizados, com uma assistência diferenciada principalmente no que tange à idade, pois cada fase da vida apresenta transformações fisiológicas e psíquicas, além de carregarem consigo o estigma da doença, a incerteza do prognóstico e forma de entendimento da morte e a vontade de viver. ${ }^{5}$

Os desafios da oncologia são maiores ainda no que diz respeito ao enfrentamento do problema de forma integral. Para isso, as ações devem compreender desde a formulação das políticas de saúde e a difusão de conhecimentos até um atendimento capaz de atender às necessidades biológicas, psicológicas e sociais do portador da doença, sendo imprescindível o pleno conhecimento dessas e sua representação para os envolvidos no processo terapêutico. ${ }^{1}$

Diante disso, o problema posto para investigação tem a seguinte questão norteadora: Quais as mudanças vivenciadas por crianças com câncer, segundo a percepção de suas mães? Nesse sentido, esse estudo teve como objetivo identificar as mudanças vivenciadas por crianças com câncer, segundo a percepção de suas mães. 


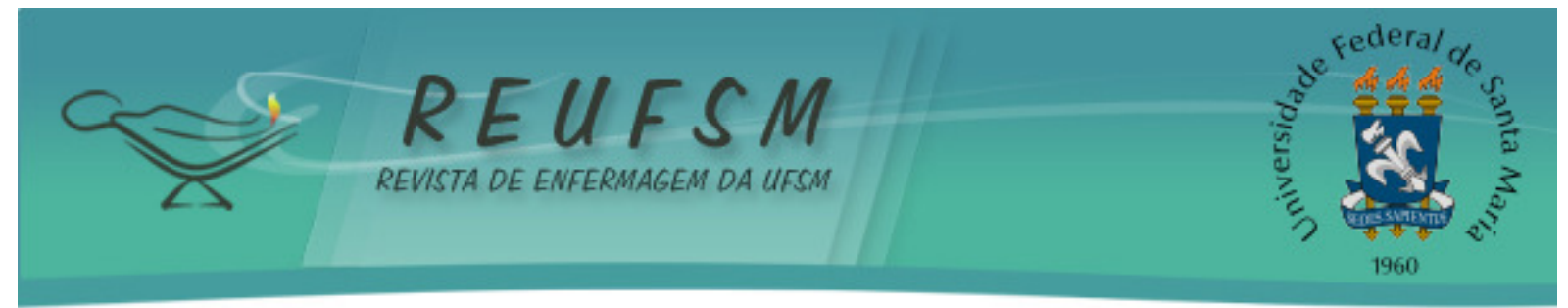

MÉTODO

Estudo descritivo-exploratório realizado na Fundação Sara Albuquerque Costa do município de Montes Claros, Minas Gerais (MG). Além de abrigo, a Fundação oferece alimentação, meios de transportes para consultas e tratamento, acompanhamento multiprofissional, doações, orientações e esclarecimentos de dúvidas para usuários cadastrados na fundação tanto de Montes Claros como de outras cidades.

As participantes do estudo foram mães de crianças com câncer atendidas pela Fundação Sara. A amostra foi composta por nove mães que apresentavam idade entre 20 e 35 anos, com prevalência de dois a quatro filhos e apenas uma das mães relatou ter passado por outra experiência com a doença dentro da própria família. Adotaram-se os seguintes critérios para inclusão na amostra nesta pesquisa: ser mãe de criança usuária da instituição; ser maior de 18 anos; estar presente nos dias previstos para a realização das entrevistas. Quanto ao critério de exclusão: mostrar-se sem condições psicológicas e/ou cognitiva na qual estas se caracterizam por déficit na percepção, memória, representação do conhecimento, linguagem e pensamento, para ser entrevistada.

Utilizou-se a entrevista semiestruturada como instrumento de coleta de dados, as quais ocorreram no interior da Fundação Sara, em local reservado e apropriado, no mês de setembro de 2012. Para a construção das informações foi utilizado um roteiro para as entrevistas, sendo que a abertura do dialogo ocorreu a partir da seguinte questão:

A) Você percebeu alguma mudança no corpo do seu filho após a doença? Se sim, quais foram? Fale sobre isso.

Participaram do estudo sete mães de crianças do gênero feminino e duas mães de crianças do gênero masculino, sendo que das nove crianças, quatro apresentava idade entre zero e quatro anos e cinco entre cinco e nove anos. As entrevistas foram realizadas após a aceitação das mães mediante assinatura do Termo de Consentimento Livre e Esclarecido. Obteve-se a saturação dos dados, ${ }^{6}$ com as repetições das respostas, quando então as entrevistas foram encerradas. As respostas foram gravadas, transcritas e digitadas na íntegra, com o objetivo de assegurar a fidedignidade de todas as informações fornecidas. A identificação das participantes foi feita através de letra e número $(M 1, M 2 . .$. a fim de preservar a identidade.

Após a coleta de dados, os mesmos foram categorizados para posterior análise e discussão com a literatura. 0 tratamento dos dados se deu através da Análise do Conteúdo ${ }^{7}$ da qual surgiram as seguintes categorias: "Descrevendo as mudanças vivenciadas pela criança na percepção das mães" e "A educação em saúde para o enfrentamento da doença". Na primeira categoria emergem três subcategorias: "Impacto psicológico do câncer no viver da criança"; "Mudanças vivenciadas no cotidiano da criança"; e "A resposta do corpo ao câncer". Já na segunda categoria emerge uma subcategoria: "Fortalecimento das ações educativas para o enfrentamento da doença".

Os preceitos éticos foram estabelecidos de acordo à Resolução 196/96 do Conselho Nacional de Saúde $(\mathrm{CNS})^{8}$ a qual regulamenta pesquisas envolvendo seres humanos. 0 projeto de pesquisa foi encaminhado e aprovado pelo Comitê de Ética em Pesquisa das Faculdades Unidas do Norte de Minas (CEP FUNORTE) sob o parecer de $N^{\circ}$. 90.945/2012, Certificado de Apresentação para Apreciação Ética (CAAE): 07203712.2.0000.5141.

\section{RESULTADOS E DISCUSSÃO}

Durante as entrevistas, foram ouvidas nove mães, quando foi alcançado o ponto de saturação das respostas. Para a compreensão dos aspectos gerais relacionados às 


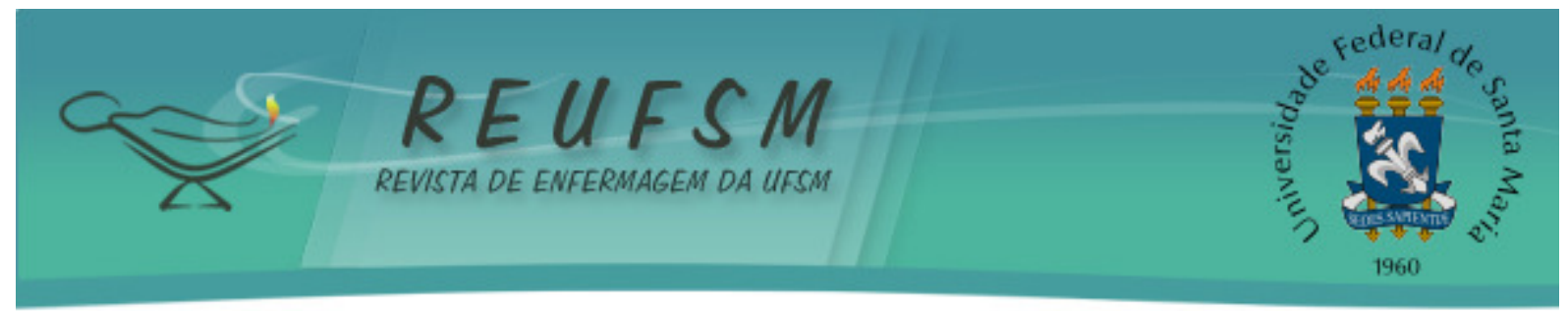

características individuais e ao tratamento, são apresentados os dados da Tabela 1 na qual relacionam fatores que influenciam diretamente nas alterações biopsicossociais das crianças.

Tabela 1: Distribuição das crianças com relação as suas características pessoais e clínicas. Montes Claros/MG, 2012.

\begin{tabular}{lccc}
\hline Variáveis & Descrição & $\mathbf{n = 9}$ & $\%$ \\
\hline Idade & $0-4$ anos & 04 & $44,4 \%$ \\
& $5-9$ anos & 05 & $55,6 \%$ \\
\hline Sexo & Feminino & 07 & $77,8 \%$ \\
& Masculino & 02 & $22,2 \%$ \\
\hline Tempo de diagnóstico do câncer & Até 01 ano & 05 & $55,6 \%$ \\
& De 01 a 05 anos & 04 & $44,4 \%$ \\
\hline Tipo de câncer & Câncer sanguíneo & 06 & $66,7 \%$ \\
& Outros & 03 & $33,3 \%$ \\
\hline Tipo de tratamento atual & Nenhum & 01 & $11,1 \%$ \\
& Quimioterapia & 06 & $66,7 \%$ \\
& Radioterapia & 01 & $11,1 \%$ \\
Procedência & Transplante & 01 & $11,1 \%$ \\
\hline Fonte & Montes Claros & 02 & $77,8 \%$ \\
& Outras cidades & 07 & $22,2 \%$ \\
\hline
\end{tabular}

Fonte: Pesquisa de campo. Montes Claros/MG. 2012.

\section{Descrevendo as mudanças vivenciadas pela criança na percepção das mães}

\section{Impacto psicológico do câncer no viver da criança}

Segundo as mães, sete das crianças apresentaram mudanças psicológicas após o acometimento do câncer. Duas mães de crianças que souberam do diagnóstico há menos de um ano referiram que não houve nenhuma mudança. Foi observado que nas duas crianças do sexo masculino na qual uma apresentava um ano e cinco meses e a segunda criança cinco anos e seis meses prevaleceu a impaciência, o nervosismo e a agressividade enquanto que as meninas apresentaram-se mais tristes e quietas:

Ele está bastante nervoso devido ao tratamento, impaciente, dependente. (M1)

Ela está dengosa e bastante curiosa em relação ao seu tratamento. (M2)

Ela tá triste, quieta e conversa pouco. (M3)

Ficou uma criança muito abatida, triste, não queria frequentar a creche, não queria saber de comer, era só deitada. (M5)

Ele ficou mais agressivo, muito nervoso, impaciente. (M6)

Ela ficou mais quieta, não conseguia andar, com medo de ficar muito tempo no hospital. (M7)

A criança, assim como o adulto, também tem suas necessidades humanas básicas. A maioria daquelas que adoecem ficam mais chorosas, dependente dos pais e o seu quadro 


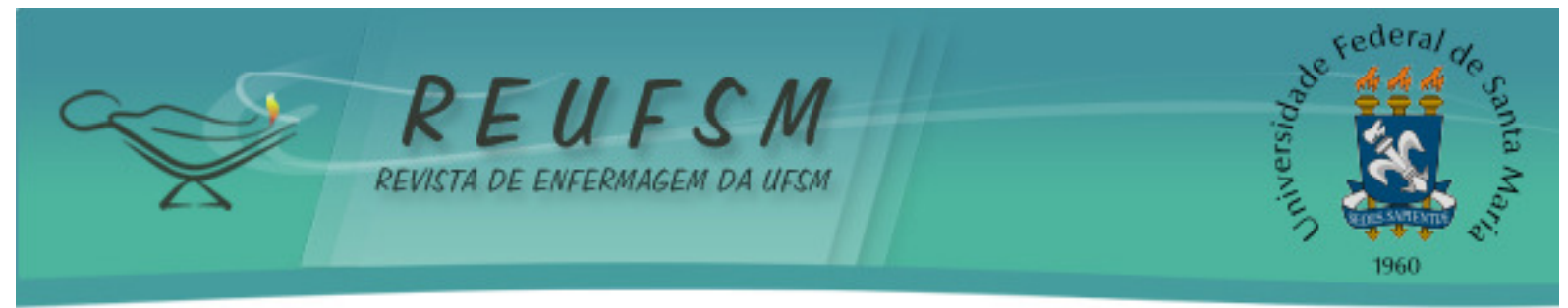

emocional tende a piorar, em função da possibilidade de afastar-se de casa e de seus familiares, por conta do ambiente hospitalar a que será submetida e dos procedimentos médicos. Ela é sujeita à passividade e é cercada de pessoas estranhas, o que traz mais dor e sofrimento. Além disso, os sinais e sintomas da doença deixam as crianças tristes, abatidas e, muitas vezes, privadas do convívio social. ${ }^{9}$

\section{Mudanças vivenciadas no cotidiano da criança}

Foi verificado que a maior parte das crianças em idade escolar estuda na cidade de origem residindo fora da cidade de Montes Claros/MG. Com isso, as mesmas abandonaram a escola em decorrência do tratamento acontecer fora da cidade de origem.

Toda semana tem trazer ele, ele não vai mais pra escola. (M6)

Ele deixou de ir para a escola, pelo fato dos cuidados que ele tem que ter quanto às brincadeiras, pelo fato da paralisia. Como ele tem que ficar mais afastado das outras crianças, ele não está querendo ir mais a escola. (M1)

A permanência no ambiente escolar, nem sempre é possível, uma vez que a rotina de uma criança em tratamento oncológico muda radicalmente. Manter a vida cotidiana, fazer planos e realizá-los passam a ser um grande desafio. As idas constantes ao hospital, as internações, muitas vezes frequentes, casos de viagens constantes e o tratamento em si e seus efeitos colaterais são algumas mudanças que ocorrem e que implicam em alterações no dia a dia. ${ }^{10}$

Assim, como o abandono das atividades escolares, outra mudança no cotidiano que possivelmente contribui para a piora no aspecto emocional das crianças é o afastamento dos amigos, que em um dos casos relatados possui um agravante, decorre do preconceito e estigma que ainda acompanham o câncer:

Os amigos dele não vão lá em casa. E eu chamo às vezes, mas eles não vão. Acho que as mães não deixam, pensam que o câncer pega. Ele come bem junto com a família, a mesma comida, nada precisa ser separado. (M6)

Uma mãe chegou até a separar os objetos de uso pessoal da filha:

No início ela só comia em prato de vidro. Na escola tinha que levar um prato, copo e colher separados, em casa também era separado. (M3)

A doença e o tratamento impõem cuidados especiais, principalmente a busca por um estilo de vida mais saudável e ações relacionadas ao estado imunológico das crianças, normalmente debilitado. Isso foi percebido a partir dos depoimentos das entrevistadas:

Na alimentação sempre tem que mudar alguma coisa, não é tudo que pode comer. (M1)

Não pode comer fora de casa, come alimentos mais ricos, mais verdes e não posso dar alguns alimentos industrializados. (M9) 


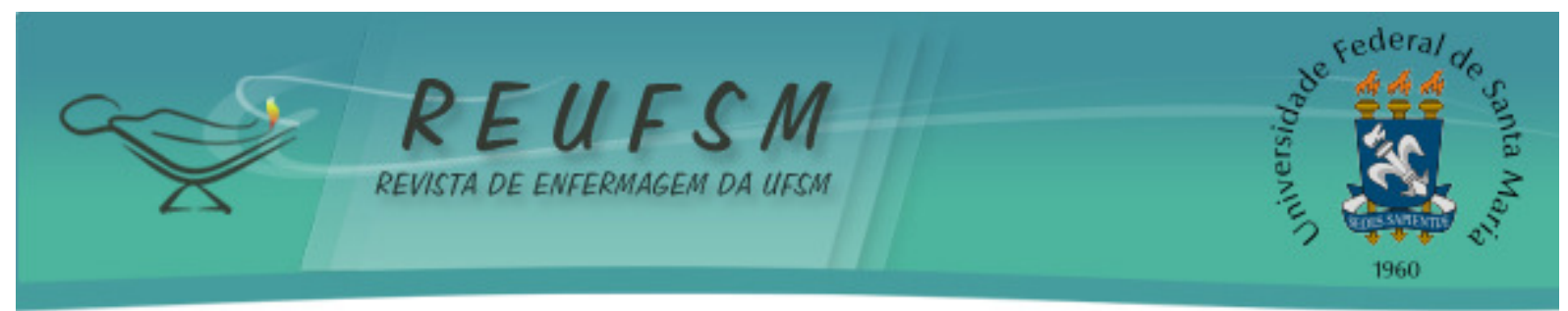

No dia a dia o banho tem que ser mais cedo, para evitar resfriados. Como está em tratamento a imunidade está baixa. Evitamos também poeiras, friagem. (M2)

Um cuidado maior sempre que for cuidar dela, lavar as mãos antes. O banho mais cedo. (M4)

Ele não gosta de ficar sozinho. Ele gostava muito de brincar, eu moro na zona rural, gostava de brincar na terra, não pode mais, fica mais assistindo televisão. (M6)

A higiene corporal, assim como a lavagem das mãos, é um cuidado que tem por finalidade principal a limpeza da pele, reduzindo a colonização microbiana através da remoção de sujidade. No caso dos pacientes em tratamentos como a quimioterapia as ações relacionadas à redução de microrganismos são fundamentais, pois em geral, ocorre o rebaixamento da imunidade passando a necessitar de cuidados especiais com a higiene e o preparo de alimentos com a finalidade de diminuir a contaminação e o risco de infecç̃̃es oportunistas. ${ }^{11}$

A alimentação adequada é essencial para auxiliar na recuperação dos pacientes em tratamento quimioterápico, dessa forma é preciso evitar a ingestão de alimentos que apresentam alto poder de contaminação. Isso inclui, além das frutas e verduras cruas, produtos industrializados ou preparados fora de casa, como também assumir uma boa alimentação e hidratação escolhendo alimentos de maior valor nutritivo, ricos em ferro, saudáveis e rigorosamente higienizados para o consumo; comer pequenas porções em intervalos menores; evitar ingestão de líquidos entre as refeições, observar a data de validade das embalagens e manter o uso individual. ${ }^{12}$

$\mathrm{Na}$ percepção de todas as mães, as várias mudanças no dia a dia das crianças muitas vezes implicaram em alterações no cotidiano de todo o grupo familiar:

Passo mais dias longe de casa, deixando filhos e esposo, tendo que dividir a família, como: eu cuidando do filho doente, e meu esposo cuidando da casa e dos outros filhos. (M1)

Toda a família passou a ter um cuidado diferenciado com a alimentação, zelo maior com a criança. Não tenho o apoio do pai da minha filha, em três anos de tratamento ele veio visitá-la uma vez. Temos apoio dos meus pais no cuidado e tratamento da minha filha. (M2)

Meu esposo teve que se afastar da empresa. Minha irmã passou a me ajudar no cuidado com minha filha. Há alguns dias minha cunhada teve que sair do emprego para me ajudar, revezando nos horários para ficar no hospital com minha filha. (M4)

Nós morávamos na roça, mudamos pra cidade, pra ela ter o conforto, atendimento melhor. (M5)

Pelas falas das mães percebe-se que a doença altera não apenas o cotidiano das crianças, mas provoca mudanças em toda a dinâmica familiar, especialmente devido às novas necessidades que surgem em função do tratamento. 


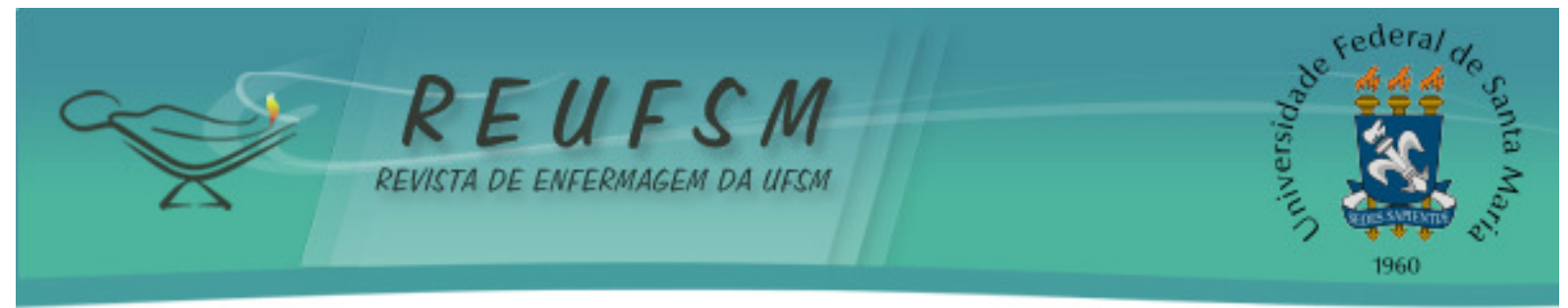

A mãe de uma criança oncológica em geral deixa em segundo plano o marido e seus demais filhos e passa a ser o principal agente que transmite carinho, afeto e segurança, provê a higiene e alimentação e auxilia no tratamento do filho. ${ }^{9}$

\section{A resposta do corpo ao câncer}

Com relação às mudanças fisiológicas e corporais, todas as crianças apresentaram alterações, segundo as mães:

Engordou, a barriga está maior, lado esquerdo do corpo paralisado, andando mais devagar, sem tato na mão esquerda. O intestino está preso, quase não está fazendo coco. (M1)

Emagreceu, queda do cabelo. (M2)

Manchas roxas pelo corpo, febre muito alta, machucados na mucosa da boca. (M4)

Inchaço, febre, não queria se alimentar, baixa de plaquetas, parou de fazer coco, o xixi era muito pouco e reclamava de dor. Os órgãos cresceram como fígado, baço, rins. Durante a quimioterapia não conseguia se alimentar, nada, tudo que comia voltava até água, queda de cabelo, ficava deitada todo o tempo. (M5)

Os problemas relatados decorrem tanto da própria doença, como do seu tratamento, como é o caso da quimioterapia, em que seis das crianças estavam em uso. Uma pesquisa realizada no município de Jundiaí, São Paulo (SP) evidenciou que a febre, anemia, perda de peso, dor óssea e manchas roxas ou hemorragias são considerados como os principais sinais de câncer pediátrico. ${ }^{13}$

A êmese, a anorexia, alopecia, anemias profundas, hemorragias, hemotransfusões e baixa resistência imunológica são apenas algumas das ocorrências que geralmente acompanham o tratamento oncológico. ${ }^{9}$ Alterações nutricionais podem ser decorrentes da ação direta no metabolismo dos quimioterápicos utilizados. A medicação antineoplásica está diretamente ligada às alterações nutricionais dos pacientes, pois os efeitos adversos da mesma tendem a influenciar indiretamente na ingestão e absorção dos alimentos. ${ }^{14}$

\section{A educação em saúde para o enfrentamento da doença}

\section{Fortalecimento das ações educativas para o enfrentamento da doença}

Observou-se que todas as mães receberam algum tipo de informação acerca da doença de seus filhos ou do tratamento proposto, a partir da análise de seus depoimentos:

Os médicos falam que é uma doença e que o tratamento é complicado e demorado, não podiam me dar uma certeza de cura, mas para ter fé em Deus. (M1)

No primeiro momento não me informaram sobre as chances que minha filha teria. Tanto que eu só pensava que ela fosse morrer. Em seguida, fui transferida para outro hospital que tinha outras crianças com os mesmos problemas ou até piores, ai fui orientada e fiquei mais 


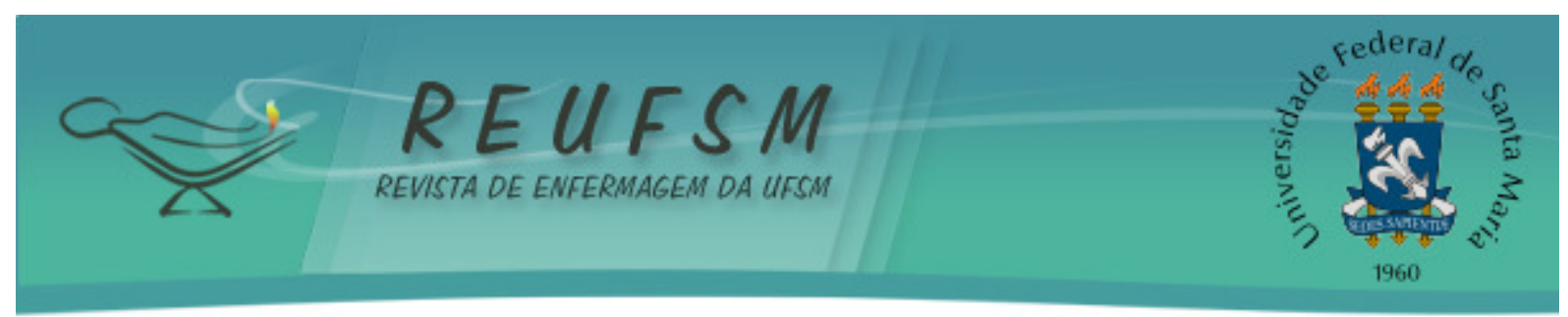

tranquila. No momento em que se chega ao hospital a fundação Sara é informada, procura saber de tudo, para nos ajudar e apoiar. (M2)

Tive poucas informações passada pela médica e de início a fundação me procurou dando apoio e querendo informações sobre a doença, mas como está precoce o diagnóstico, temos que esperar mais respostas da médica. (M3)

Tive orientações médicas de que é uma doença bem complicada, mas que tem chances de cura com o tratamento. (M4)

Percebeu-se, no entanto, que as informações passadas às mães pelos profissionais inicialmente, foram, de forma geral, superficiais e que, muitas vezes, o processo de educação em saúde para o controle da doença não aconteceu em momento oportuno.

A equipe multidisciplinar, por meio da integralidade dos cuidados especializados, viabiliza o conforto necessário para todos aqueles que estão envolvidos no processo de tratamento, assim como o esclarecimento de questões que permeiam o longo acompanhamento do paciente oncológico, tornando-se fundamental para que a família possa lidar adequadamente com os novos desafios. ${ }^{15}$

$\mathrm{Na}$ maioria das vezes o médico foi citado como o profissional que passou às mães as informações descritas. Em nenhum dos relatos foi mencionado a ação de uma equipe multiprofissional ou do enfermeiro no processo de educação em saúde, embora capacitar as famílias e a criança para o enfrentamento da nova realidade, o câncer, é uma intervenção que deve fazer parte da assistência do enfermeiro. ${ }^{9}$ Algumas mães referiram buscar informações também a partir de outras fontes:

Pesquisei na internet $e$ as pessoas da minha cidade, com mais informações sobre a doença, me procuravam para conversar. (M2)

As mães, diante dos desafios impostos pelo tratamento, utilizam de estratégias que incluem busca por suporte social, por informações sobre a doença em muitos meios de comunicação ou mesmo com pessoas próximas e o aumento de práticas religiosas. ${ }^{16}$

A oferta de um cuidado integral e de qualidade é fundamental no cotidiano da assistência de pacientes com câncer, em que cada profissional faz o que há de melhor dentro do que está ao seu alcance para amenizar os efeitos da manifestação da neoplasia e de seu tratamento. Para a eficácia do tratamento, ao evitar o sentimento, torna-se possível o distanciamento do paciente até o ponto em que este e sua patologia não influenciem no estado psicoemocional da equipe. ${ }^{17}$

As falas das mães mostraram que elas detêm conhecimentos sobre alguns aspectos da doença, especialmente com relação aos cuidados com o seu filho e como lidar com as mudanças, tendo pouca informação sobre o conceito e evolução clínica da doença. Não foi possível identificar a atuação do enfermeiro no processo de educação em saúde para o enfrentamento da doença.

\section{CONSIDERAÇÕES FINAIS}

Com a realização da pesquisa foi possível perceber que a maioria das crianças cujas mães participaram do estudo é do sexo feminino, portadora de câncer sanguíneo, estava em quimioterapia, recebeu diagnóstico da doença há até um ano e reside em outros municípios de Minas Gerais. As mães relataram mudanças em vários campos da vida dos filhos. Com relação às alterações emocionais, foi interessante observar a diferença de comportamento entre crianças 


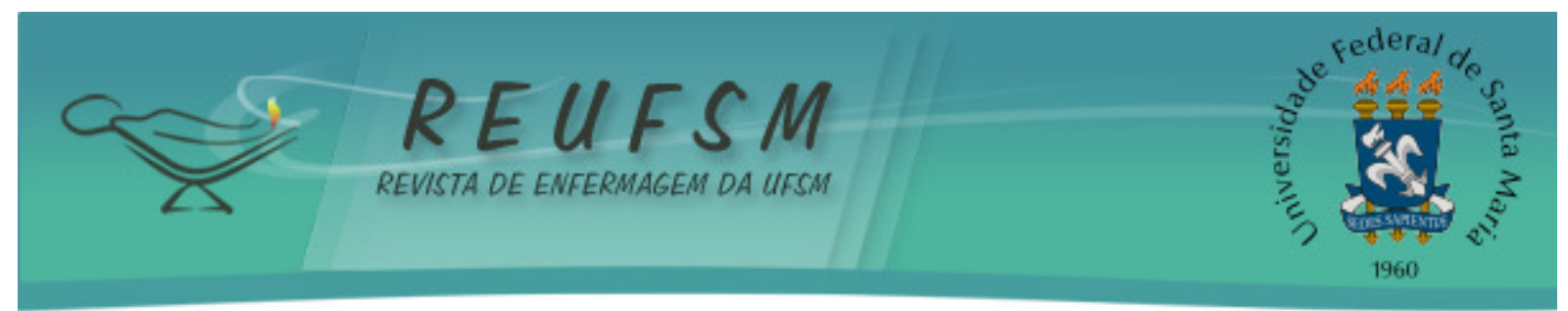

do sexo masculino, em que prevaleceu a impaciência, nervosismo e o comportamento agressivo, enquanto que as crianças do sexo feminino se mostraram mais tristes e quietas.

As principais mudanças no cotidiano das crianças foram a privação do contato com amigos e o abandono da escola, fatos que contribuem para o comprometimento das relações sociais da criança e para o agravamento das repercussões emocionais e psicológicas relatadas. A família também apresentou diversas modificações no seu dia a dia com a finalidade de atender as necessidades dos filhos, relacionadas ao câncer e ao seu plano terapêutico. Como alterações físicas e fisiológicas, foram relatados efeitos decorrentes da doença e também associados ao tratamento quimioterápico: queda de cabelo, perda de apetite, constipação intestinal, vômitos, anemias e imunossupressão.

Conclui-se que os pacientes oncológicos e os seus familiares precisam conviver com incertezas, riscos, alterações na rotina familiar, social, educacional, restrições físicas, experiências de ansiedade, perdas, mudanças, o que demanda assistência de uma equipe multidisciplinar, com atuação eficaz do enfermeiro, sobretudo no aspecto da educação do paciente e da família, a fim de sanar as dúvidas, orientar e capacitar para o cuidado, diminuir os anseios, encorajar para um tratamento bem sucedido. Recomenda-se o desenvolvimento de novos estudos a respeito do tema, para que haja subsídios suficientes para instrumentar ações de melhorias no atendimento às crianças com câncer e suas famílias.

\section{REFERÊNCIAS}

1. Tavares EC, Segóvia AC, Paula ES. A família frente ao tratamento da criança com câncer: revisão de literatura. Rev Fafibe Online [Internet]. 2007 [acesso em 2010 maio 20];3(3):1-5. Disponivel em: http://www.unifafibe.com.br/revistasonline/arquivos/revistafafibeonline/sumario/11/190 42010103543.pdf.

2. Mohallem AGC, Rodrigues AB, organizadores. Enfermagem oncológica. $1^{\text {a }}$ ed. São Paulo (SP): Editora Manole; 2007.

3. Calil AM, Prado C. O ensino de oncologia na formação do enfermeiro. Rev Bras Enferm [Internet]. 2009 [acesso em 2010 ago 12];62(3):467-70. Disponível em: http: //www.scielo.br/pdf/reben/v62n3/22.pdf.

4. Amador DD, Gomes IP, Coutinho SED, Costa TNA, Collet N. Concepção dos enfermeiros acerca da capacitação no cuidado à criança com câncer. Texto \& Contexto Enferm [Internet]. 2011 [acesso em 2012 jan 23];20(1):94-101. Disponível em: http://www.scielo.br/pdf/tce/v20n1/11.pdf.

5. Peterson AA, Carvalho EC. Comunicação terapêutica na Enfermagem: dificuldades para o cuidar de idosos com câncer. Rev Bras Enferm [Internet]. 2011 [acesso em 2012 mar 30];64(4):692-7. Disponível em: http://www.scielo.br/pdf/reben/v64n4/a10v64n4.pdf.

6. Fontanella BJB, Ricas J, Turato ER. Amostragem por saturação em pesquisas qualitativas em saúde: contribuições teóricas. Cad Saúde Pública [Internet]. 2008 [acesso em 2014 jul 21];24(1):17-27. Disponível em: http://www.scielosp.org/pdf/csp/v24n1/02.pdf.

7. Moraes R. Análise de conteúdo. Rev Educ [Internet]. 1999 [acesso em 2013 ago 22];22(37):7-32. Disponível

http://cliente.argo.com.br/ mgos/analise_de_conteudo_moraes.html.

8. Brasil. Ministério da Saúde. Conselho Nacional de Saúde. Comissão Nacional de Ética em Pesquisa. Resolução $\mathrm{n}^{\circ}$ 196, de 10 de outubro de 1996. Aprova diretrizes e normas regulamentadoras de pesquisas envolvendo seres humanos [Internet]. Prefeitura Municipal 


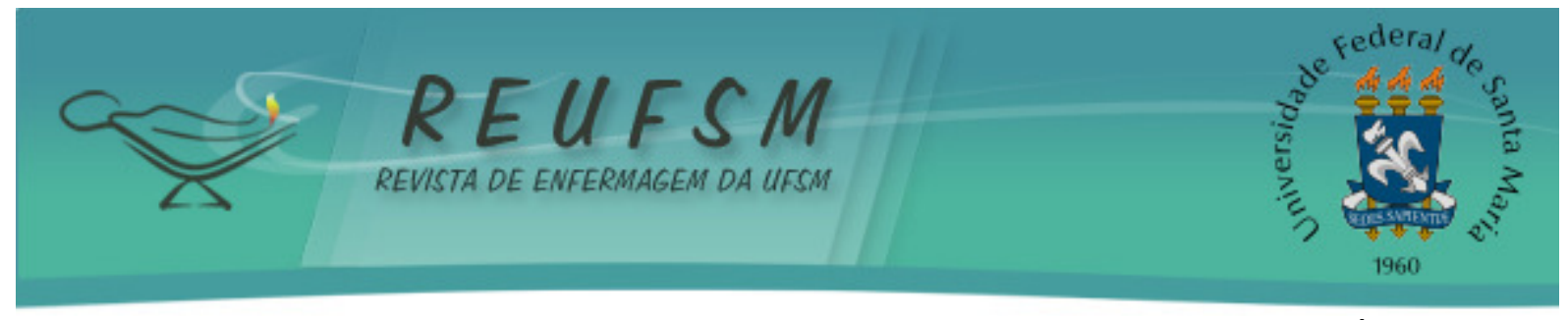

de São Paulo. [acesso em 2014 jul 21]. Disponível em: http://www.prefeitura.sp.gov.br/cidade/secretarias/upload/saude/arquivos/comiteetica/ Reso196.pdf.

9. Silva DS, Martins MR. A brincadeira na terapia de recuperação oncológica infantil. Rev Uningá Review [Internet]. 2011 [acesso em 2012 mar 20];8(1):31-40. Disponível em: http://www.mastereditora.com.br/periodico/20130803_1612002.pdf.

10. Rocha MCM, Antunes MAM. Mutilação pelo câncer: articulações entre saúde, psicologia e educação. Mundo saúde [Internet]. 2012 [acesso em 2012 nov 11];36(2):276-83. Disponível em: http://www.saocamilo-sp.br/pdf/mundo_saude/93/art02.pdf.

11. Silva JB, Kirschbaum DIR, Oliveira I. Significado atribuído pelo enfermeiro ao cuidado prestado a criança doente crônica hospitalizada acompanhada de familiar. Rev Gaúcha Enferm [Internet]. 2007 [acesso em $2011 \mathrm{dez}$ 9];28(2):250-9. Disponível em: http://seer.ufrgs.br/RevistaGauchadeEnfermagem/article/view/3176/1749.

12. Abreu ES, Simony RF, Takahashi AA, Santos CRB. Recomendações nutricionais para crianças que realizaram transplante de medula óssea. Rev Cienc Med Biol [Internet]. 2012 [acesso em 2012 dez 14];11(1):54-9. Disponível em: http: / / www. portalseer.ufba.br/index.php/cmbio/article/viewFile/5838/4452.

13. Borges JBR, Loggetto S, Giatti MJL, Camargo ACM, Pereira ACP, Miazaki AP, et al. Caracterização das pacientes, na infância e adolescência, portadoras de câncer no município de Jundiaí e região. Rev Bras Cancerol [Internet]. 2009 [acesso em 2010 set 20];55(4):337-43. http://www1.inca.gov.br/rbc/n_55/v04/pdf/337_artigo3.pdf.

em:

14. Caprara GL, Ricalde SR, Santos JS. Características nutricionais dos pacientes oncológicos pediátricos do Hospital Geral de Caxias do Sul. Pediatr [Internet]. 2009 [acesso em 2011 jun 20];31(4):234-41. Disponível em: http://www.pediatriasaopaulo.usp.br/upload/pdf/1314.pdf.

15. Menezes CNB, Passareli PM, Drude FS, Santos MA, Valle ERM. Câncer infantil: organização familiar e doença. Rev Mal-Estar Subj [Internet]. 2007 [acesso em 2011 jul 25];7(1):191-210. Disponível em: http://pepsic.bvsalud.org/pdf/malestar/v7n1/11.pdf.

16. Kohlsdorf M. Aspectos psicossociais no câncer pediátrico: estudo sobre literatura brasileira publicada entre 2000 e 2009. Psicol Rev [Internet]. 2010 [acesso em $2011 \mathrm{fev}$ 1];16(2):271-94. Disponível em: http://periodicos.pucminas.br/index.php/psicologiaemrevista/article/view/P.16789563.2010v16n2p271/1938.

17. Salimena AMO, Teixeira SR, Amorim TV, Paiva ACPC, Melo MCSC. Estratégias de enfrentamento usadas por enfermeiros ao cuidar de pacientes oncológicos. Rev Enferm UFSM [Internet]. 2013 [acesso 2013 ago 22];3(1):8-16. Disponível em: http://cascavel.ufsm.br/revistas/ojs-2.2.2/index.php/reufsm/article/view/6638/pdf.

Data de recebimento: $17 / 08 / 2013$

Data de aceite: 22/07/2014

Contato com autor responsável: Patrick Leonardo Nogueira da Silva

Endereço postal: Avenida Doutor Sidney Chaves, 1171, Apto 102/H, B: Edgar Pereira, Montes Claros, Minas Gerais, Brasil. CEP: 39400-648

E-mail: patrick_mocesp70@hotmail.com 